\title{
A relevância da interdisciplinaridade para a compreensão dos danos causados pela indústria de confecção de Maringá
}

\author{
Paula Piva Linkel
}

\section{Resumo}

Esse texto tem como objetivo discutir a forma como a ciência pós-normal e a interdisciplinaridade podem indicar caminhos para a reflexão cientifica acerca dos danos causados pela indústria de confecção de Maringá. O texto está dividido em três partes, inicialmente apresenta-se o conceito de sociedade de risco de Beck, em seguida a problemática dos resíduos sólidos da confecção no município de Maringá. Finalmente assinala-se a importância da ciência pósnormal e da interdisciplinaridade como caminhos que podem contribuir no desenvolvimento e compreensão da complexidade desta questão. Os resíduos sólidos da indústria da confecção precisam ser observados sob diversos pontos de vista, considerando o meio ambiente por meio da sustentabilidade, as normativas legais por meio do governo e o ponto de vista do empresário. Não basta apenas a atuação do governo, mas uma participação mais ampla por parte dos empresários e mesmo da comunidade envolvida com essa problemática, portanto a interdisciplinaridade e a ciência pós-normal mostram-se ferramentas importantes que auxiliam na compreensão das variáveis que fazem parte dessa questão.

Palavras-chave: Ciência; Confecção; Resíduos 


\section{Apresentação}

Maringá é considerado pólo de moda do Sul do país, sendo que sua alta produtividade causa danos ambientais e afeta a dinâmica urbana. São produzidas aproximadamente sete milhões de peças por mês, produção distribuída entre as mais de 1600 empresas que compõem o arranjo produtivo do município e geram entre $12 \%$ e $25 \%$ dessa produção em resíduos que impactam sobre o meio (SINDVEST, 2012).

A partir dessa perspectiva objetiva-se nesse texto, discutir a forma como a ciência pós-normal e a interdisciplinaridade podem indicar caminhos para a reflexão cientifica acerca dos danos causados pela indústria de confecção de Maringá. Trata-se de uma pesquisa exploratória com o intuito de apresentar algumas questões fundamentais para se entender os impactos ambientais do setor da moda. Para tanto, o texto inicia com um panorama referente à sociedade de risco e à complexidade dos problemas enfrentados, citando como exemplo a problemática referente ao setor de confecção na cidade de Maringá, especificamente a questão dos resíduos sólidos da confecção. Em seguida a problemática de pesquisa a ser desenvolvida no decorrer do meu doutorado. Posteriormente se aponta como ferramentas para compreender tais problemas a ciência pós-normal, conceito criado por Funtowicz e Ravetz, e a interdisciplinaridade como novos olhares sobre a ciência e a complexidade dos problemas que envolvem as questões ambientais.

Para a pesquisa a ser desenvolvida no decorrer do doutorado, a interdisciplinaridade é fator fundamental para o sucesso da mesma. A interdisciplinaridade permite articular diferentes áreas do conhecimento sob a ótica da ciência ambiental, como por exemplo: administração, engenharia de produção, gestão ambiental, gestão de resíduos, moda e legislação (PHILIPPI, 2011).

\section{Sociedade de risco}

As atividades humanas, via de regra, causam perturbações ao meio ambiente. Essas perturbações variam conforme o tipo de atividade executada (DREW, 2002). As ações antrópicas não apenas degradam o meio, mas o alteram, portanto, o ambiente inclui não somente o meio natural, mas também o ambiente construído (JAMIESON, 2010, p. 01). Ao considerar o ambiente como uma junção entre o meio natural e o meio alterado pelo homem percebe-se uma relação complexa na qual as ações humanas interferem diretamente sobre a natureza e as conseqüências variam em grau de intensidade, afetando a qualidade de vida da sociedade.

O processo de degradação do meio ampliou-se devido ao desenvolvimento e a intensificação do processo de industrialização (DREW, 2002). O autor prossegue afirmando ainda que face a esses acontecimentos, a partir da segunda metade do século XX, iniciou-se uma mobilização que gerou uma série de convenções e atitudes em relação ao meio ambiente, repensando o papel do mesmo na manutenção da vida. Foi a partir desse momento que surgiram conceitos como desenvolvimento sustentável e sustentabilidade (DREW, 2002).

Embora algumas atitudes tenham sido tomadas em prol do ambiente, a degradação do meio trouxe conseqüências que se refletem em problemas de larga escala. Esse processo de reflexão sobre as questões ambientais que envolvem a sociedade levaram ao surgimento de várias discussões. Uma dessas discussões refere-se às teorias do sociólogo Ulrick Beck que desenvolveu o conceito de sociedade de risco (CURRAN, 2013).

Beck afirma que a sociedade de risco surgiu a partir do momento em que incorporou o progresso como ideologia, pois degradou o capital natural de forma violenta e agora passa por um processo de auto-confrontação, tendo que conviver com riscos catastróficos (BECK, 2008). O autor prossegue afirmando que "a sociedade industrial pode ser descrita como uma forma de sociedade que fabrica suas conseqüências negativas. [...] Então, posto que suas instituições geram e legitimam perigos que não podem controlar, a sociedade industrial se vê e se critica como sociedade de risco" (BECK, 2008, p. 157).

Em outras palavras o processo industrial trouxe benefícios como a tecnologia, mas ao mesmo tempo conseqüências inesperadas. Portanto, "argumentar que "modernização reflexiva" envolve maior complexidade e feedback dos efeitos entre ação social e os resultados naturais é uma reivindicação plausível e importante" (CURRAN, 2013, p. 48). Esse processo de auto-confrontação se dá por meio da reflexão, na qual a sociedade começa a se tornar consciente dos agravos ambientais que vem enfrentando (BECK, 2008).

Embora a teoria de Beck seja criticada em alguns aspectos por alguns pesquisadores como Dean Curran, membro do Departamento de Sociologia da Queen's Universit, há pontos positivos que devem ser destacados. Curran (2013) critica Beck por desconsiderar o conceito de "classe" na compreensão dessa nova realidade, a sociedade de risco.

No entanto, apesar dessa crítica, Curran aponta os aspectos positivos das teorias de Beck, reforçando algumas questões. O autor salienta que "os crescentes riscos dos efeitos colaterais de intervenções sobre a natureza vem a partir do crescimento do nosso poder para controlar e intervir na natureza" (CURRAN, 2013, p. 47). Esse poder de intervenção sobre a natureza causou e ainda causa riscos incalculáveis.

Os problemas que aparecem na sociedade de risco existiam anteriormente, no entanto, agora eles assumem proporções catastróficas e apresentam-se de forma extremamente complexa, variando na escala de tempo e espaço principalmente no que se refere às questões ambientais. (BECK, 2008). Boa parte deles foram criados pelo processo de industrialização desenfreada e a expansão da ciência que transcendeu os laboratórios, criando novas tecnologias com impactos pesados sobre o meio natural (MARTINEZ ALIER, 2007).

Em outras palavras a técnociência promoveu a produção de problemas em larga escala, como conseqüência dos avanços tecnológicos (ALVARENGA, 2011). Esses 
problemas que geram riscos e perigos são extremamente complexos e exigem uma reflexão sobre o papel da ciência, das instituições e do Estado como produtor desses riscos, ao passo que a sociedade herda passivos ambientais das tecnologias aplicadas antes dos testes (BECK, 2008).

As mudanças climáticas são um exemplo, essa problemática envolve não apenas a comunidade científica, mas as instituições, o Estado e a sociedade civil. A governança ambiental e as decisões a serem tomadas devem levar em consideração os riscos e as conseqüências desses riscos que podem transforma-se em perigo para a sociedade (BECK, 2008). Mas para avaliar esses risos e perigos há a necessidade de conhecer as causas, os efeitos e a amplitude dos problemas de forma integrada e profunda, para que as decisões tomadas possam de fato surtir algum efeito.

As questões ambientais envolvem uma série de situações com diversos graus de complexidade. Cito como exemplo, a problemática que se refere à questão ambiental relativa ao setor da confecção no município de Maringá, mais especificamente os resíduos sólidos, retalhos de tecido. O setor de confecção traz benefícios como empregos, mas afeta o meio ambiente, em outras palavras envolve diferentes atores sociais com interesses próprios em torno da produção e destinação dos resíduos sólidos (empresários e autoridades legais) como enfatiza Berlin (2012).

A confecção é uma das fases finais de produção do vestuário, posteriormente ocorrem os acabamentos por meio das estamparias e lavanderias. A indústria da confecção é responsável pela montagem da roupa, seu arranjo produtivo inicia-se com o processo de desenvolvimento de coleção, escolha do material, modelagem, pilotagem, ajustes, enfesto, corte, montagem, acabamentos, revisão das peças e venda (BERLIM, 2012).

Os resíduos desse setor variam de acordo com o segmento de produto, por exemplo, confecções de malhas ou tecidos planos apresentam insumos diferenciados, no entanto, os resíduos normalmente são: papel, plástico, sobras de tecido, tubetes, retalhos de tecido, aparas de tecido, lixas de corte, embalagens de aviamentos, rebarbas de overloque, sobras de linha, fio, estopas e óleo, papelão e peças defeituosas que não podem ser comercializadas (GUIMARÃES, MARTINS, 2010).

O problema não se refere somente ao montante de resíduos produzidos, mas a suas composições, com fibras naturais, sintéticas e artificiais, assim como uma densa variedade de corantes e fixadores. Dessa forma, esse material representa um risco ao meio ambiente. A complexidade do problema mostra-se alarmante devido a quantidade de variedade de composições dos tecidos, químicos utilizados no seu beneficiamento e a segmentação de produção das confecções, material esse que provoca a contaminação do solo e mesmo perigo a saúde quando contaminado com óleo de máquina, por exemplo (MILAN. 2010).

Nesse caso a discussão em torno do problema envolve a comunidade de empresários, o poder público, a população e as empresas que fazem a coleta dos materiais e mesmo as ONG's que os utilizam na fabricação de artesanato.
Os resíduos circulam pela cidade causando impactos variados ao meio e a população (MILAN. 2010).

Na seqüência apresento com mais clareza a importância do setor da confecção para o município de Maringá e suas dimensões. Apontando as normativas legais e ressaltando a importância de aprofundar as pesquisas nesta temática com a finalidade de compreender a complexidade do setor e a forma como ele impacta na cidade.

\section{A problemática da confecção no município de Maringá}

O Brasil é um dos poucos países que detém toda a cadeia produtiva no setor têxtil, desde a produção da fibra à produção de roupas (BERLIM, 2012). O país engloba toda a cadeia de produção: produção da fibra, fiação, tecelagem, tinturaria, lavanderia, confecção e varejo.

De acordo com a ABIT (Associação Brasileira da Indústria Têxtil), o país possui em torno de $30 \mathrm{mil}$ empresas no setor, que fazem do país o $4^{\circ}$ maior produtor de confeccionados do mundo, com uma produção média de 9,8 bilhões de peças por ano (ABIT, 2011).

Essa produção toda está distribuída pelos diversos estados e cidades brasileiras. Nesse setor, destacase o Paraná, com o corredor da Moda formado pelas cidades de Cianorte, Maringá e Londrina. O município de Maringá é considerado pólo de moda do sul do país, com uma produção de aproximadamente sete milhões de peças/mês, emprega cerca de um terço da população no setor têxtil direta ou indiretamente. Tal setor possui grande importância para a cidade, contudo traz também problemas, pois seu sistema produtivo gera resíduos que comprometem o meio ambiente (SINDVEST, 2012).

De acordo com Lillan Berlin (2012), Gabriel Sperandio Milan (2010) e Kate Fletcher (2011), os danos causados pela cadeia têxtil referem-se principalmente à contaminação do solo e da água, além do ar, pela geração de odores. Em relação ao solo, essa se dá pelo uso de agrotóxicos, pelo despejo de material solidificado proveniente do beneficiamento e de retalhos de tecido originários da confecção. A contaminação da água ocorre em função do despejo de efluentes procedentes do beneficiamento, geralmente carregados com corantes, fixadores e alvejantes (WALTERS. 2005). A contaminação ocorre em todo o processo industrial, desde o início, com a produção da fibra (HERTWICH, 2010; MARTINUZZI, 2011).

Para melhor compreender os danos causados por tal indústria é preciso mapear cada atividade e avaliar cautelosamente o seu desenvolvimento dentro da cadeia de produção (HERTWICH, 2010, MARTINUZZI, 2011 e MACIEL, 2012). Toda essa cadeia de produção engloba setores com produtos variados, no entanto, dentre esses produtos destaca-se a vestimenta, uma produção que "ocupa um espaço de distinção entre os bens que consumimos e fabricamos” (BERLIM, 2012, p. 20).

As roupas são produzidas por um processo específico, a confecção, que consiste no desenvolvimento de produto, modelagem, pilotagem, planejamento de produção, produção, acabamentos, revisão e embalagem (SENAI, 
2007). O processo de produção gera descartes em todas as fases, sendo uma das mais expressivas o processo de corte, que origina retalhos de tecidos (EPA, 1997; MACIEL, 2012). A eliminação total da geração desses resíduos é inviável e, por essa razão, a redução, o correto tratamento e destinação final de resíduos adquirem especial importância (CNTL, 2009).

A escolha do município de Maringá justifica-se pelo fato de ser uma cidade pólo na produção de moda do sul do país (SINDVEST, 2012). O Estado do Paraná possui cerca de $9 \%$ das indústrias confeccionistas do país, conta com aproximadamente quatro mil estabelecimentos produtivos (VIDIGAL, 2009). Na região de Maringá, havia 1200 empresas em 2009, na atualidade há em torno de 1666 empresas que se localizam no município. O setor emprega cerca de 100 mil trabalhadores direta e indiretamente, produzindo aproximadamente sete milhões de peças por mês (SINDVEST, 2012). Esse montante de empresas demonstra a importância do setor para o município que possui 357 mil habitantes, dos quais, praticamente um terço está empregado no ramo têxtil.

Maringá movimenta mais de R\$ 140 milhões no mercado nacional e internacional. Parte do que é confeccionado também fomenta o setor atacadista da cidade, que engloba quatro shoppings atacadistas [...] que recebem $15 \mathrm{mil}$ compradores todo mês (SINDVEST, 2012, p. 01).

A alta produtividade do setor e seu crescimento não se fazem sem danos ambientais identificados por Generoso de Angelis Neto e Patrícia Cardoso (2011). Esses autores destacam os danos causados pelo descarte de retalhos de tecido devido ao "seu alto poder de inflamabilidade e no montante, que geram grandes volumes [...] esgotando rapidamente espaços e contaminando os solos" (CARDOSO, ANGELIS NETO, 2011, p. 01).

No caso das confecções, os resíduos são formados ao longo da ação produtiva que gera diferentes subprodutos (SENAI, 2007), resultando em "impactos ambientais e sociais ao longo do ciclo de vida das roupas" (DAFRA, 2010, p. 02).

A variedade de resíduos é descartada de forma incorreta, ou ainda, destinada a entidades sociais que nem sempre conseguem aproveitar todo o material e depositam o que não aproveitam em locais inadequados (LIMA JÚNIOR, 2010). Em uma cidade como Maringá, em que a produtividade chega a aproximadamente sete milhões de peças/mês, a quantidade de resíduos gerados é exorbitante, em média $12 \%$ a $25 \%$ do montante produzido (SINDVEST, 2012).

Em se tratando do município de Maringá, que faz parte do principal aglomerado industrial (cluster) do Estado do Paraná (LIMA JUNIOR, 2010), há a necessidade de analisar com mais precisão os impactos ambientais causados pelo descarte de resíduos. Portanto, busca-se analisar o processo de produção da indústria de confecções de vestuário em Maringá, PR, em especial o descarte de materiais decorrentes do processo de corte e verificar em que medida é possível adotar mecanismos de Produção mais Limpa $(\mathrm{P}+\mathrm{L})$ aplicados à modelagem, enfesto e corte nas empresas selecionadas. Deste modo, buscase avaliar se no município de Maringá, as confecções utilizam tecnologias limpas capazes de tornar a empresa menos agressiva.

Para responder a esse questionamento foram levantadas as seguintes hipóteses: os procedimentos que envolvem a produção mais limpa e a gestão ambiental podem tornar a confecção menos agressiva ao meio ambiente; a falta de tecnologias, mão-de-obra qualificada e processos adequados promovem maior geração de resíduos; Os resíduos da confecção tornam-se mais perigosos quando contaminados, impedindo o reaproveitamento e ou a reciclagem.

Deve-se lembrar que esta produção têxtil está inserida na dinâmica urbana e que se espera que a mesma seja capaz de se adequar às demandas ambientais, com programas que diminuam os resíduos, ampliem o gerenciamento, reaproveitamento e reciclagem dos mesmos. Isso porque tais resíduos não são apenas um problema do empresário, mas de todo o município, que tem que adotar políticas públicas para controlar tais problemas (RAMOS, 2009).

Não se pode ignorar que há normas ambientais que regulam como deve ser o descarte de resíduos sólidos. Podese citar a Constituição Brasileira em seu Artigo 225, que dispõe sobre a proteção ao meio ambiente; a Lei 6.938/81, que estabelece a Política Nacional de Meio Ambiente; a Lei 6.803/80, que dispõe sobre as diretrizes básicas para o zoneamento industrial em áreas críticas de poluição. Há também outras regulamentações como as resoluções do Conselho Nacional do Meio Ambiente - CONAMA 257/263 e 258, os Capítulos 19, 20 e 21 da Agenda 21

Além de tais leis há também as normas da ABNT NBR 10004:2004, que discute exclusivamente a questão dos resíduos sólidos, sua periculosidade e classificação para que possam ser gerenciados corretamente.

Recentemente outras leis foram estabelecidas, dentre elas, a Lei Federal n 10.165/2000: todas as empresas que exercem atividades potencialmente poluidoras e utilizadoras de recursos naturais passaram a ser contribuintes da TCFA - Taxa de Controle e Fiscalização Ambiental. Outra lei que teve impacto direto sobre o setor têxtil é a Lei n⿳0 12.305, de 02 de agosto de 2010 que Institui a Política Nacional de Resíduos Sólidos, que dispõe, sobretudo a respeito das diretrizes relativas à gestão integrada e ao gerenciamento de resíduos sólidos.

Face às regulamentações vigentes, o município de Maringá apresenta normatizações para controlar a produção e a correta destinação destes resíduos. O Termo de Referência (2009) foi preparado pela Secretaria Municipal do Meio Ambiente e emitido às empresas do APL pela Prefeitura Municipal de Maringá, o qual foi elaborado com base nas legislações Municipal, Estadual e Federal e nas normas técnicas vigentes para o gerenciamento de resíduos. Em síntese, o termo trata aspectos gerais sobre a elaboração do Plano de Gerenciamento Integrado de Resíduos (PGIR).

Mesmo com tais regulamentações vigentes, há ainda problemas sérios referentes ao município de Maringá. As empresas precisam aprender a diminuir seus impactos e resíduos, assim como gerenciá-los de forma correta. 
Francisco Rodrigues Lima Júnior realizou em 2010 uma pesquisa junto a 08 empresas no município de Maringá, verificando a situação dos resíduos.

[...] somente $25 \%$ das empresas possuem um local específico para armazenagem de resíduos. A maioria das empresas armazena os resíduos no chão de fábrica e em locais de armazenagem de outros materiais, somente $50 \%$ das empresas entrevistadas possuem um PGRS e 50\% ofereceu treinamento aos funcionários com relação aos procedimentos de separação, armazenagem e transferência de resíduos (LIMA JÙNIOR, 2010, p. 08).

Os dados mostram as deficiências na armazenagem, gerenciamento e correta destinação dos resíduos sólidos, que muitas vezes são depositados em lixões ou terrenos baldios, não raras vezes indo parar em corpos d'água, afetando assim a qualidade de vida dos indivíduos e mesmo a dinâmica urbana (CARDOSO, ANGELIS NETO, 2011).

Deve-se lembrar que o processo de circulação dos resíduos contraria o disposto no Plano de Gerenciamento de Resíduos Sólidos estabelecido pelo município. Mesmo que a Política Nacional de Resíduos Sólidos, Lei nº. 12.305/2010, que em seu Art. 3º inciso XI, apresente a gestão integrada de resíduos sólidos, ainda há resistências por parte do setor da confecção em cumprir as determinações legais. A gestão integrada é um conjunto de ações voltadas para a busca de soluções para os resíduos sólidos, de forma a considerar as dimensões política, econômica, ambiental, cultural e social, com controle social e sob a premissa do desenvolvimento sustentável. Essa é apenas uma das ferramentas a serem utilizadas, outras opções seriam a produção mais limpa, o eco design e a gestão ambiental, por exemplo.

Para que a produção seja limpa, é necessário que todo o processo o seja: isso implica pensar no que fazer com a grande quantidade de retalhos de tecido gerados pelo processo de confecção. Tais resíduos são gerados no setor de corte, onde ocorre, na maioria das vezes, grande desperdício devido à falta de tecnologia que auxiliem no encaixe de moldes (EPA, 1997; ARAÚJO, 1996). Não basta apenas pensar o resíduo, mas a gestão de todo o processo, é preciso pensar as entradas e saídas da empresa.

Isso significa que não basta apenas melhorar os processos para que se tornem menos agressivos, mas sim adotar procedimentos e atitudes que envolvam maior sensibilidade com a causa ambiental por parte dos empresários e colaboradores da empresa.

Por essas razões, em se tratando da indústria de confecções de Maringá, há a necessidade de melhor otimizar o processo de produção não somente para reduzir o volume de resíduos gerados, como também para minimizar os danos ambientais causados particularmente pelo descarte desse material.

Para desenvolver essa pesquisa é preciso pensar em metodologias que englobem não apenas um único campo do conhecimento, mas é necessário englobar questões políticas, sociais e culturais relacionadas ao meio ambiente e produtivas relacionadas a engenharia de produção e moda.

\section{Novos caminhos para a pesquisa}

O sistema produtivo da confecção gera uma variedade de resíduos, o mais impactante nesse caso, seria o retalho de tecido. A composição, a coloração e os acabamentos que esses retalhos recebem os fazem assumir características particulares o que dificulta, por exemplo, pensar em um processo de reciclagem que junte todo tipo de tecido. Além dessas questões, cabe destacar a conscientização do empresário em seguir as normativas e trinar seus funcionários para gerenciar esses resíduos.

Outro fator importante é o arranjo produtivo e composição dos tecidos que muda a cada nova coleção. A quantidade de variáveis que está presente nesse sistema produtivo é bastante ampla. Portanto, pensar essa problemática requer um olhar mais amplo, não apenas referente à administração de produção, moda, ou mesmo ambiental, mas sim a integração entre essas áreas do conhecimento.

Cabe lembrar ainda que além do ambiente interno, o ambiente externo também influencia a confecção, como por exemplo, políticas públicas, tecnologias e mesmo os sindicatos do setor. Portanto, a meu ver, pensar essa problemática exige repensar nas formas de aplicar metodologias e mesmo de conceber a produção do conhecimento.

Assim sendo, a complexidade dos problemas atuais exige novas fermentas de pesquisa e novos olhares sobre a forma de "fazer ciência".

Ao discutir os desafios que a complexidade coloca à ciência moderna, Edgar Morin permite que observemos como a mesma se apresenta como questão nuclear na atualidade por apontar, de um lado, os limites do conhecimento disciplinar e de outro, a importância da busca de novas formas de entendimento da realidade (ALVARENGA, 2011, p. 18).

A realidade atual é extremamente complexa e exige novos olhares sobre os objetos de pesquisa. A ciência pós-normal e a interdisciplinaridade podem auxiliar na compreensão de problemas com maior grau de complexidade e da realidade que os engloba. A ciência dita "tradicional" apresenta restrições no que se refere à compreensão de alguns dos fenômenos atuais, como afirmam Funtowicz e Ravetz (2003).

A mentalidade científica tradicional 'normal' fomenta expectativas de regularidade, simplicidade e certeza nos fenômenos e nas nossas intervenções. Mas estes podem inibir o crescimento de nossa compreensão dos novos problemas e de métodos adequados para a sua solução (FUNTOWICZ; RAVETZ, 2003, p.02).

Muito mais do que métodos de pesquisa para solucionar problemas, Van De Hove (2007) aponta que a ciência, na linguagem cotidiana, refere-se a um método específico para descobrir e criar novos conhecimentos, sendo cada conhecimento enquadrado em diferentes ramos da ciência. Esses diferentes ramos das ciências, que não interagem entre si, nem sempre são capazes de responder a certas problemáticas isoladamente. 
Por exemplo, ao trabalhar com as questões referentes aos resíduos sólidos da confecção, utilizar apenas a engenharia de produção como base não possibilita uma compreensão mais ampla das dificuldades, pois muitas vezes a situação encontrada não se refere apenas a processos produtivos, mas sim a formas de pensar. Ao usar apenas a gestão da produção nem sempre é possível mapear os danos causados pelos retalhos ou conscientizar os empresários. Alguns objetos exigem a integração de diferentes áreas do conhecimento para que possam ser explorados e compreendidos face a sua complexidade.

$\mathrm{O}$ autor prossegue afirmando que:

[...] a ciência é também um processo social, inserida em um contexto social, envolvendo atores e instituições. Estas múltiplas facetas da "ciência" sugerem que, durante a pesquisa para os domínios de intersecção entre ciência e política, vemos sucessivamente nas saídas da ciência, seus processos, seus atores e seu contexto (VAN DE HOVE, 2007, p. 809).

Portanto, a partir do momento em que a ciência normal é incapaz de lidar com a complexidade e a escala dos problemas ambientais atuais de forma integrada, houve a necessidade de se pensar em novas formas de se "fazer ciência," uma dessas novas formas seria a ciência pós-normal. "O conceito de ciência pós-normal foi desenvolvido por Funtowicz e Ravetz, representa um grande avanço no sentido de um entendimento diferente da ciência e, em particular, as suas relações com a política" (VAN DE HOVE, 2007, p. 807-808). De acordo com Funtowicz e Ravetz ciência pós-normal (PNS) é:

[...] É uma nova concepção de gestão de questões complexas relacionadas com a ciência. Ele se concentra em aspectos da resolução de problemas que tendem a ser negligenciadas em pesquisas tradicionais da prática científica: a incerteza, agregamento de valores, e uma pluralidade de perspectivas legítimas. PNS $^{\mathrm{I}}$ considera estes elementos como parte integrante da ciência (FUNTOWICZ; RAVETZ, 2003, p.01).

Em outras palavras, a ciência pós-normal possibilita maior integração entre o conhecimento e as pesquisas desenvolvidas e a resolução de problemas por meio da tomada de decisão e participação da sociedade civil ou de instituições, havendo assim maior integração entre a sociedade e a ciência.

Van De Hove (2007) acrescenta afirmando que a ciência se desenrola no âmbito social e natural, havendo uma interdependência entre eles, visto que em muitos casos a ciência influencia ou é influenciada pelos ambientes sociais e naturais. Outra questão a ser explorada no que diz respeito à ciência pós-normal e a valorização de conhecimentos que não são considerados científicos. "PNS fornece um fundamento em que este conhecimento tradicional é utilizado, harmonizado, melhorado e validado novamente" (FUNTOWICZ; RAVETZ, 2003, p.07).

Ao considerar o conhecimento tradicional como contribuinte na construção do conhecimento a ciência

PNS- Post-normal Science. pós-normal abre portas para a experimentação. No caso da confecção isso é fundamental, principalmente no que se refere às confecções de pequeno porte, pois em muitos casos, mais do que a aquisição de novas tecnologias é necessário reavaliar processos, tradicionais, recriando-os por meio de testes e experimentações para adequá-los a realidade da empresa.

A ciência pós-normal busca pensar os problemas de forma integrada, levando em consideração a ciência, os conhecimento tradicional e a resolução de problemas. Em uma sociedade de risco onde a complexidade dos problemas é cada vez maior, há a necessidade de olhálos de forma interativa. Os problemas atuais não são necessariamente complicados, mas apresentam maior grau de complexidade, pois envolvem sistemas interligados e muitas vezes interdependentes em variados níveis e escalas (FUNTOWICZ; RAVETZ, 2003).

Os autores afirmam ainda que "PNS foi desenvolvido como a metodologia adequada para a integração com os sistemas naturais e sociais complexos" (FUNTOWICZ; RAVETZ, 2003, p.02). Busca-se, portanto, uma maior interação entre a ciência e a política, principalmente no que se refere à governança ambiental.

A complexidade das ações humanas afeta o meio, deve-se lembrar que a governança ambiental ou políticas voltadas para o meio ambiente não envolvem apenas o poder público, mas a sociedade civil que é afetada diretamente por ela, em muitos casos os empresários tem grandes responsabilidades pois devem se adequar as novas demandas. $\mathrm{O}$ mesmo ocorre com a confecção, os empresários devem se adequar as normativas legais e tornar suas empresas menos impactantes. O ambiente político-legal corresponde ao macro ambiente que interfere nas ações e tomadas de decisão dentro das empresas. Portanto, compreender a problemática da confecção envolve os ambientes externos e internos e sua inter-relação, principalmente por que envolvem a tomada de decisão onde os valores assumem papel fundamental na forma como as empresas vêem as questões ambientais.

As idéias e conceitos pertencentes a égide do PNS testemunham o surgimento de novas estratégias de resolução de problemas em que o papel da ciência é apreciado em seu contexto total da complexidade e incerteza dos sistemas naturais e da relevância dos compromissos e valores humanos (FUNTOWICZ; RAVETZ, 2003, p. 01).

As novas estratégias de resolução de problemas, no que se refere à ciência pós-normal, incorpora também a tomada de decisão e a interação entre aqueles que tomam tais decisões e a ciência (VAN DE HOVE, 2007).

Martinez Alier (2007) compartilha dessa visão ao afirmar que a ciência pode ser aplicada a temas políticos como as estratégias de resolução de problemas. O desenvolvimento de novas metodologias aplicadas à ciência implica na qualidade da informação analisada sob diversos pontos de vista. "A frase incerteza transmite o problema, não diz respeito à descoberta de algum fato, mas a compreensão ou de gestão de uma realidade intrinsecamente complexa" (MARTINEZ ALIER, 2007, p. 37). 
Os problemas atuais, que fazem parte da sociedade de risco, apresentam-se em escalas diversas e com alto grau de complexidade exigindo da ciência e dos cientistas novos olhares e perspectivas. Além da ciência pós-normal, outras perspectivas podem ser aplicadas a ciência. Uma dessas perspectivas é compreender que os problemas não são isolados, mas suas causas e efeitos possuem origens variadas, o que exige uma visão mais completa e holística do mesmo. Para dar conta desse tipo de dificuldade muitas vezes é necessário incorporar elementos pertencentes a outros campos do conhecimento.

Uma interação circular vai assim estabelecendo-se entre a ciência e as técnicas como espaço de surgimento de novos conceitos, novos paradigmas, desejos e projetos dos indivíduos e das sociedades que dispõem de meios sempre mais eficientes para torná-los realidade; e, enfim, as próprias reações não previstas, inesperadas dos sistemas físico-maturais modificados, que fazem emergir novas questões, novos desafios, à ciência, às técnicas e às sociedades (PHILIPPI, 2011, p. 72).

Uma das formas de lidar com a complexidade dos problemas do mundo atual é utilizar a interdisciplinaridade como ferramenta que auxilia a compreender a relação dos problemas e os diversos conhecimentos que o compõem. A interdisciplinaridade se propõe a:

[...] operar nas fronteiras disciplinares e na re-ligação de saberes, tendo como finalidade última dar conta dos fenômenos complexos de diferentes naturezas. [...] busca responder a problemas gerados pelo próprio avanço da ciência moderna disciplinar (ALVARENGA, 2011, p. 21).

A afirmativa de Alvarenga nos permite compreender as dificuldades e os problemas da ciência convencional, no entanto, a "interdisciplinaridade não deve se tornar uma nova exigência para toda e qualquer produção científica [...]. São certos objetos e assuntos que necessitam de colaboração entre diferentes disciplinas para serem adequadamente estudados" (PHILIPPI, 2011, p. 87).

Algumas problemáticas ou objetos de pesquisa exigem a colaboração entre as ciências sociais e naturais para que possam ser compreendidos de forma mais eficaz. "A condição básica do êxito da colaboração entre as ciências sociais e as ciências naturais reside no reconhecimento, por cada grupo de disciplinas de pertinência, até para responder a seu próprio questionamento, do que acontece no domínio da realidade explorado pelo outro grupo" (PHILIPPI, 2011, p. 99).

$\mathrm{O}$ reconhecimento entre os dois grupos permite o transito e a construção do conhecimento de forma integrada, no entanto deve-se salientar que reconhecer a importância de outras áreas do conhecimento ou trabalhar de forma interdisciplinar não significa de maneira alguma desconsiderar as ciências duras, pelo contrário, para que novos avanços sejam alcançados ainda há a necessidade das ciências ditas duras, ou mais fechadas.

O que deve ocorrer é uma maior integração entre ambas, evitando rivalidades ou classificações dos fenômenos e ações humanas, visto que as formas de pensar influenciam as formas de agir e o ambiente que o ser humano constrói. Assim sendo, "as ciências sociais devem reconhecer a natureza profundamente ambivalente da pessoa humana e das sociedades [...], ao mesmo tempo essencialmente ideacional ou imaterial e profundamente arraigada na matéria, [...] a parte não social do social (PHILIPPI, 2011, p. 99). O autor prossegue afirmando que:

Por outro lado as ciências físicas e naturais devem admitir que as produções da mente humana [...] não são meras fantasias que viriam enfeitar ou mascarar uma realidade, mais essencial e mais determinante, que seria a realidade da matéria. Devem aceitar que a dimensão social, cultural, faz parte integrante da realidade e desempenha um papel determinante, tanto na história das sociedades quanto nas dos ecossistemas que estudam (PHILIPPI, 2011, p. 99-100).

Em outras palavras as dimensões naturais e sociais estão conectadas, pois ambas são influenciadas pelas ações e formas de pensar que causam interferências no mundo natural, material e intelectual. Transitar entre as diversas áreas do conhecimento, em casos específicos, é uma boa forma de compreender de forma ampliada a rede de conexões das problemáticas que envolvem o ambiente.

Uma problemática que demanda maior interação entre as ciências sociais e naturais refere-se aos impactos da indústria da confecção, visto que muitas vezes as questões ambientais não são exploradas ou contempladas nas decisões empresariais. Para compreensão dessa temática, mais do que compreender os impactos e as causas, é necessário observar como as decisões são tomadas e como o empresário e os colaboradores vêem esse novo cenário.

Em se tratando de um projeto que busca compreender os efeitos da indústria da confecção a interdisciplinaridade mostra-se como um facilitador, visto que é necessário uma visão mais ampla e o conhecimento de diferentes áreas, como por exemplo, administração, engenharia de produção, gestão ambiental, gestão de resíduos, moda e legislação, o que permite uma visão mais completa da problemática estudada.

No entanto cabe salientar que estes conhecimentos devem voltar-se para a compreensão de como o processo produtivo e os resíduos da confecção afetam o meio ambiente, conseqüentemente, uso tais conhecimentos como base para compreender e estabelecer conexões com a questão ambiental, olhando-os de uma perspectiva da ciência ambiental e não de forma isolada. Observa-se, nesse caso, uma problemática que envolve diversos atores socais com interesses distintos.

\section{Considerações Finais}

Com o objetivo de discutir a forma como a ciência pós-normal e a interdisciplinaridade podem indicar caminhos para a reflexão cientifica acerca dos danos causados pela indústria de confecções de Maringá, a qual servirá de base para propor caminhos que possam diminuir esses danos observa-se que a problemática dos resíduos sólidos da indústria da confecção na cidade de 
Maringá, PR mostra-se complexa, pois envolve diversos atores socais com interesses distintos.

Os resíduos sólidos da indústria da confecção precisam ser observados sob diversos pontos de vista, considerando o meio ambiente por meio da sustentabilidade, as normativas legais por meio do governo e o ponto de vista do empresário. Não basta apenas a atuação do governo, mas uma participação mais ampla por parte dos empresários e mesmo da comunidade envolvida com essa problemática.

Cabe ressaltar que esta problemática faz parte de um problema gerado pelo desenvolvimento e ampliação da industrialização e da tecnologia, o que não envolve apenas questões de gestão de chão de fábrica, mas a visão dos empresários e mesmo atitudes de governança ambiental. Esse problema vincula-se a sociedade de risco e mesmo a ciência pós-normal ao exigir uma interação em maior grau entre a ciência e política, No entanto, a interdisciplinaridade mostra-se como ferramenta fundamental para a compreensão da extensão do problema ao passo que possibilita a vinculação entre diferentes áreas do conhecimento como: moda, gestão da produção, administração, legislação e ciência ambiental, que possibilitam uma visão mais completa e integrada das variáveis que envolvem essa questão.

A abordagem interdisciplinar não só contribui, mas é fundamental para o desenvolvimento da pesquisa, já que são necessárias diferentes áreas do conhecimento para a realização e conclusão da pesquisa, o que permite ao pesquisador uma abrangência temática do conhecimento, mais aberta e capaz de levar a uma reflexão mais profunda das diversas questões que afetam o meio ambiente, visto que no caso específico dessa problemática, há uma série de processos, fatores culturais e sociais que afetam a dinâmica da confecção e seus impactos.

\section{Referências}

ABIT. Dados gerais da indústria da moda brasileira referentes ao ano de 2011, 2011. Disponível em: http://www.texbrasil.com.br/texbrasil/SobreSetor. aspx?tipo $=15 \&$ pag $=1 \&$ nav $=0 \&$ tela=SobreSetor .

ABNT, NBR 10.004, Resíduos sólidos: classificação. Associação Brasileira de NormasTécnicas, Rio de Janeiro, 2004. Disnponível em: http://www.aslaa.com.br/legislacoes/ NBR\%20n\%2010004-2004.pdf.

ALVARENGA, A. et al. Histórico, fundamentos filosoficos e teórico-metodologicos da interdisciplinaridade. In: PHILIPPI, A. et al. Interdisciplinaridade em Ciência, Tecnologia e Inovação. Manole, São Paulo, 2011

ARAÚJO, Mário de. Tecnologia do vestuário. Lisboa: Fundaçao Calouste Gulbenkian, 1996.

BECK, Ulrich. La sociedad del riesgo mundial. Barcelona: Paidós, 2008.
BERLIM, Lilyan. Moda e sustentabilidade: uma reflexão necessária. São Paulo: Estação das Letras e Cores, 2012.

CARDOSO, Patrícia M.; ANGELIS NETO, Generoso de. Diagnóstico dos resíduos sólidos de uma cadeia produtiva têxtil- um estudo de caso. In: VII EPCC: Encontro Internacional de produção científica, 2011.

CNTL. Produção mais limpa em confecções. Disponível em: www.senairs.org.br/cntl.Acessado em: 15 mai. 2009.

CONAMA - Conselho Nacional do Meio Ambiente. Disponível em: www.mma.gov.br/conama. Acessado em: 19 de agosto de 2013.

CURRAN, Dean. Risk society and the distribution of bads: theorizing class in the risk society. The British Journal of Sociology 2013.

DAFRA. Sustainable Clothing Action Plan. Published by the Department for Environment, Food and Rural Affairs. London, 2010.

DREW, David. Processos interativos homem-meio ambiente. 5ํㅡ. Rio de Janeiro: Bertrand Brasil, 2002.

EPA. Profile of the Textile Industry. Office of Enforcement and Compliance Assurance. U.S. Environmental Protection Agency. Washington, DC, 1997.

FLETCHER, Kate \& GROSE, Lynda: Moda \& Sustentabilidade: design para mudança. São Paulo: Editora Senac, 2011.

FUNTOWICZ, S. O. y RAVETZ, J. Post Normal Science. International Society for Ecological Economics: 2003.

GUIMARAES, Bárbara; MARTINS, Suzana Barreto. Proposta de metodologia de prevenção de resíduos e otimização de produção aplicada à indústria de confecção de pequeno e médio porte. PROJÉTICA, v. 1, p. 184-200, 2010.

HERTWICH. Edgar G. et al. Assessing the Environmental Impacts of Consumption and Production: Priority Products and Materials. A Report of the Working Group on the Environmental Impacts of Products and Materials to the International Panel for Sustainable Resource Management. UNEP, 2010.

JAMIESON, Dale. Ética e Ambiente. São Paulo: SENAC, 2010

LIMA JUNIOR, F. R. ; FRACAROLLI, R. L.; GALDAMEZ, E. V. C. . Gestão de Resíduos Têxteis: Um Estudo de Caso em Um Arranjo Produtivo do Setor de Vestuário. In: XII Encontro Internacional sobre Gestão Empresarial e Meio Ambiente, 2010. Anais do XII Encontro Internacional sobre Gestão Empresarial e Meio Ambiente, 2010. 
MACIEL, Dulce Maria Holanda. Materiais têxteis e a sustentabilidade. In: VIII Colóquio de Moda, 5을 Congresso Internacional. $8^{\circ}, 2012$, Rio de Janeiro, anais VIII Colóquio de Moda, 2012.

MARTINUZZI, André; et al. CSR Activities and Impacts of theTextile Sector. Research Institute for Managing Sustainability (RIMAS). Vienna University of Economics and Business. Vienna, Austria. 2011.

MARTÍNEZ ALIER. Joan. O Ecologismo dos pobres: conflitos ambientais e linguagens de valoração. Contexto: São Paulo, 2007.

MILAN, Gabriel Sperandio. et al. Um estudo sobre a redução de resíduos têxteis e de impactos ambientais em uma indústria de confecções do vestuário. In: VI Congresso de Excelência em Gestão. Agosto de 2010.

PHILIPPI, A. et al. Interdisciplinaridade em Ciência, Tecnologia e Inovação. Manole, São Paulo, 2011

RAMOS, Fabiana M. S. Tratamento de resíduos sólidos da indústria têxtil. Dissertação de Mestrado - Engenharia Química, área de Gestão, Controle e Preservação Ambiental. Universidade estadual de Maringá: Maringá, 2009.

SENAI. Produção mais Limpa em Confecções. SENAI - Departamento Regional do Rio Grande do Sul. - Porto Alegre, 2007.

SINDVEST. Time de celebridades marcam Semana de Moda do Maringá Fashion Mix Primavera/ Verão 2013. Disponível : http://www.sindvestmaringa.com.br/site/ noticias/time-de-celebridades-marcam-semana-de-moda-domaringa-fashion-mix-primavera--verao-2013/18. acesso em: 13/10/2012.

VAN DE HOVE, Sybille. A rationale for Science-Policy Interfaces. Elsevier: 2007

VIDIGAL. Vinícius Gonçalves. et al. Interação, cooperação e ações conjuntas no arranjo produtivo local (APL) de confecção de Maringá. In: Acta Scientiarum. Human and Social Sciences. Maringá, v. 31, n. 2, p. 123-129, 2009. WALTERS, A. et al. An Overview of Textiles Processing and Related Environmental Concerns. Greenpeace Research Laboratories, Department of Biological Sciences, University of Exeter, Exeter EX4 4PS, UK. 2005. 